\title{
Health and epidemiological approaches of Trypanosoma evansi and equine infectious anemia virus in naturally infected horses at southern Pantanal
}

\author{
Daniela R. Parreira ${ }^{a}$, Ana M. Jansen ${ }^{a}$, Urbano G.P. Abreu ${ }^{c}$, Gabriel C. Macedo ${ }^{b}$, \\ Antônia R.S. Silva ${ }^{\mathrm{d}}$, Carlos Mazur $^{\mathrm{d}}$, Gisele B. Andrade ${ }^{\mathrm{b}}$, Heitor M. Herrera ${ }^{\mathrm{b}, *}$ \\ a Fundação Oswaldo Cruz - FIOCRUZ, Rio de Janeiro, CEP 21040-900, Brazil \\ ${ }^{\mathrm{b}}$ Universidade Católica Dom Bosco - UCDB, Campo Grande, CEP 79117-900, Brazil \\ c Empresa Brasileira de Pesquisa Agropecuária - EMBRAPA Pantanal, Corumbá, CEP 79320-900, Brazil \\ d Universidade Federal Rural do Rio de Janeiro - UFRRJ, Seropédica, CEP 23890-000, Brazil
}

\section{A R T I C L E I N F O}

\section{Article history:}

Received 28 March 2016

Received in revised form 3 August 2016

Accepted 3 August 2016

Available online 4 August 2016

\section{Keywords:}

Horses

EIAV

Health

Trypanosoma evansi

Pantanal

\begin{abstract}
A B S T R A C T
Equine infectious anemia virus (EIAV) and Trypanossoma evansi are endemic in Brazilian Pantanal Biome, an important area for livestock production. In this sense, we evaluated the epidemiological single and co-infection effects of T. evansi and EIAV in naturally infected horses in the southern Pantanal wetland by serological tests and hematological assays. Both higher seroprevalence and heath poor condition of the sampled animals were associated with differences in horse management between farms. We found that the negative animals for both infectious agents (NN) represented the major group in F1 (37\%), and the smallest group in F2 (19\%). Furthermore, we recorded higher EIAV seroprevalence (56\%) in F2, compared to F1 (38\%). We observed that T. evansi infection was mostly related to young horses, as seen by their higher seroprevalence, ranging from $70.7 \%$ in the beginning of the rainy season to $81 \%$ in the end of flood period, in comparison with the values of $42 \%$ and $68 \%$, respectively, in working animals. on the other hand, working animals showed a higher seroprevalence for EIAV (48\%) in both seasons than young horses. We observed that the management of working horses could be a risk factor of EIAV infection. On the other hand, as T. evansi is maintained in the study region by many species of wild mammals, the mechanical transmission through blood-sucking vectors ensures the infection to horses since early. Our results showed that single or co-infection by EIAV and T. evansi caused different degree of anemia in the infected animals. Moreover, the health of horses in Brazilian Pantanal is also influenced by differences in horse management and environmental circumstances.
\end{abstract}

(c) 2016 Elsevier B.V. All rights reserved.

\section{Introduction}

In classic epidemiology, the clinical presentation of a particular infectious disease is understood as a product of an intricate relationship involving an infectious agent, the host's immune response and environmental factors. However, parasites co-occur widely and the consequences of these interactions are poorly understood (Grenfell and Dobson, 1995; Cox, 2001; Pfaff and Candolfi, 2003; McKay, 2006; Rohani et al., 2008). Indeed, co-infections are an important emerging area of research in health and clinical care (Singer, 2010).

\footnotetext{
* Corresponding author.

E-mail address: herrera@ucdb.br (H.M. Herrera).
}

A blood protozoan Trypanosoma evansi (Kinetoplastida, Trypanosomatidae) is a monomorphic and extracellular parasite mechanically transmitted by blood-sucking flies (Tabanidae and Stomoxydae) in many tropical and sub-tropical areas around the world (Hoare, 1972; Gardiner and Mahmoud, 1990). In the Brazilian Pantanal, a vast flood plain in the core of South Amarica, $T$. evansi is enzootic, infecting both domestic (dogs, horses, bovines, buffaloes and sheep) and wild animal species (coati, capybara, bats, small rodents, marsupials, armadillos, feral pigs, collared peccary and white-lipped peccary) (Dávila et al., 2003; Herrera et al., 2004, 2005, 2008). When T. evansi causes severe disease in horses we can observe severe anemia, immunosuppression, and nervous symptomatology shown by hind-limb paresis (Silva et al., 1995a,b). In the Pantanal, trypanosomiasis by T. evansi is locally called "mal de cadeiras" and sick animals are usually treated by diminazene acetu- 
rate (7 mg/kg). Nevertheless, Seidl et al. (2001) reported that about $13 \%$ of the horses in this region can be expected to die due to $T$. evansi if no treated.

Equine infectious anemia (EIA) is a disease of considerable importance to equine health due to its immunosuppressive effects and severe anemia that significantly impairs animal performance (Issel and Coggins, 1979; Cheevers and McGuire, 1985; Cook et al., 2013). The EIAV (Retroviridae, Lentivirus) is also mechanically transmitted by large hematophagus insects, including Stomoxys calcitrans (stable fly) and Tabanus sp. (horse fly) (Baldacchino et al., 2013, 2014). However, transmission assigned to humans by using contaminated needles and other fomites plays an important role in EIAV dissemination (Issel and Foil, 1984; Barros and Foil, 2007). The endemicity of EIAV has been reported in the southeastern and northern Pantanal wetland, with seroprevalences ranging from $24.8 \%$ to 31.5\% respectively (Silva et al., 1999; Borges et al., 2013).

Although they belong to different taxa, T. evansi and EIAV are transmitted mechanically by blood-sucking flies and cause severe anemia and immunosuppression in horses. Due to environmental features, socioeconomic traits, and public policies, these diseases remain endemic in some areas of Brazil, including Pantanal region (Silva et al., 1995b, 1999; Seidl et al., 2001; Borges et al., 2013). Horses are indispensable to the traditional extensive cattle ranching in the Pantanal wetland and the health effects of single or co-infection by T. evansi and EIAV are still poorly described. In this sense, we evaluated the risk factors associated with the occurrence of T. evansi and EIAV, as well as the health status of naturally single and co-infected horses at the southern Pantanal.

\section{Materials and methods}

\subsection{Study area and collected samples}

The Brazilian Pantanal is a large $\left(160,000 \mathrm{~km}^{2}\right)$ seasonal flood plain, bordering Bolivia and Paraguay. In this biome, four million livestock sustain an important economic activity in extensive cattle raising, sharing the same habitats with abundant wildlife. The most distinctive features of this region are annual alternative periods of flood and dry, that have strongly varied in intensity through the years. The vegetation is characterized by exuberant native grass at summer, the rainy season. However, at the end of summer the grassland becomes flooded and during the drought, it becomes fibrous and water is extremely scarce. This highly seasonal climate affects the behavior, spatial distribution, and body condition of both domestic livestock and wild animals (Pozer and Nogueira, 2004; Junk et al., 2006).

In order to know the T. evansi and EIAV seroprevalences in the studied area, and determine whether there were differences between cattle ranches, at the first excursion (January 2012) we collected blood samples from all adult working horses in two distinct farms from the southern Pantanal, $30 \mathrm{~km}$ distant from each other: $F 1(n=73)$ and F2 $(n=32)$. In F1, the management of working horses consisted in a rotation system using two groups of horses. Additionally, only one group of working horses was in the service at a time. On the other hand, animals in F2 were submitted to the service throughout the year and always kept in a restricted area with low availability of pasture. Moreover, horses in F2 shared fomites and needles. In contrast to F2, animals in F1 were subjected to an annual vaccination program against rabies, encephalitis and influenza, as well as deworming (ivermectin and organophosphate) two times per year.

To evaluate if the hematological parameters of the horses would be influenced by (i) infection with EIAV and T. evansi (separately or together), (ii) environmental conditions and (iii) the age of the animals, we collected blood sample from all horses of F1 $(n=108)$ in two times: beginning of flood season (December 2012) and at the end of the rainy season (April 2013). These horses were divided into two categories: (A) untrained young horses, not in service (12-30 months old) ( $n=58)$; and (B) working tamed animals (over three years old) $(n=50)$. Working horses (category B) were subjected to more physical effort due to the long distances they roamed (often in flooded areas) and management with cattle. Unlike the untrained animals that are bred dispersed over large areas (over 1,000 ha), working horses remained in restricted places, close to each other, for approximately 40 days, according to the cattle management, favoring the mechanical transmission by blood sucking flies.

Blood was collected via jugular puncture, conditioned in sterile tubes containing anticoagulant (ethylenediamine tetraacetic acid, EDTA), and kept refrigerated for a maximum of six hours to perform parasitological and hematological assays. Serum samples were obtained from blood collected in tubes without anticoagulant and kept frozen at $-4{ }^{\circ} \mathrm{C}$ until the serologic tests. Blood collection was approved by the Ethics Committee on Animal Use (CEUA) of Universidade Católica Dom Bosco/UCDB, Mato Grosso do Sul, Brazil (registration number 021/2015).

\subsection{Laboratory procedures}

In the field laboratory, during the first six hours after blood collection, we quantified the Packed Cell Volume (PCV), using a micro-centrifuge, and counted Red Blood Cell (RBC) and White Blood Cell (WBC) in Neubauer chambers. Blood smears for WBC differential count were fixed with methanol and stained with May-Grunwald Giemsa. The mean corpuscular volume (MCV) was calculated from the results obtained in the RBC and PCV values. In this study, we considered the PCV, RBC and MCV as health condition indicators; monocyte and neutrophils counts as indicators of infection responses; and lymphocyte counts as an indicator of immune active response.

The parasitological test for $T$. evansi was performed during the first six hours after blood collection, in duplicate, according to Microhaematocrit Centrifuge Technique (MHCT) described by Woo (1970). The seroprevalence of T. evansi infection was detected by the Indirect Fluorescence Antibody Technique (IFAT), according to Camargo (1964). The antigen for T. evansi was obtained by ion exchange chromatography on DEAE cellulose column (Lanham and Godfrey, 1970) from cryopreserved T. evansi parasited blood expanded in rats immunossupressed with $40 \mathrm{mg} / \mathrm{kg}$ of cyclophosphamide three days before inoculation. All animal handling procedures had the permission of the Ethics Committee on Animal Use (CEUA) of the Instituto Oswaldo Cruz/FIOCRUZ, Rio de Janeiro, Brazil (registration number: P0292-06). As previously described by Herrera et al. (2004), the positive control serum of the reaction was coming from the positive animals in parasitological MHCT with titre $\geq 1 / 640$. Negative controls were obtained from horses bred in Rio de Janeiro, a $T$. evansi free area. The cut off ( $\geq 1: 40$ ) was considered as the lower titer of serum samples in which parasites could be detected by MHCT.

The seroprevalence of EIAV infection was detected by the Agar Gel Immunodiffusion Test (AGID) according to Coggins et al. (1972). We used a kit commercialized by Bruch Laboratory (http://bruch. com.br/005/07) currently approved by the Brazilian government, obtained by the collaboration of the Laboratory of Veterinary Virus Diseases of the Federal Rural University of Rio de Janeiro (UFRRJ).

\subsection{Statistical analysis}

The difference between the averages of the hematological values obtained in F1 and F2 and in the two management categories within F1 (untrained young horses and working tamed animals) were tested by the Mann-Whitney test. To investigate the influence 
Table 1

Seroprevalence of T. evansi and EIAV in different groups of infection in the two sampled farms of the southern Pantanal. NN - negative animals for both T. evansi and AIE virus infection; PN - positive animals only for T. evansi infection; NP positive animals only for AIE virus infection; PP - co-infected animals by T. evansi and AIE virus. The absolute number is followed by the percentage in parenthesis. Statistical differences at $\mathrm{p}<0.005$ are marked with asterisks.

\begin{tabular}{lll}
\hline Groups & F1 & F2 \\
\hline NN & $27(37.0)^{*}$ & $6(18.8)^{*}$ \\
NP & $12(16.4)^{*}$ & $9(28.1)^{*}$ \\
PN & $18(24.7)$ & $8(25.0)$ \\
PP & $16(21.9)$ & $9(28.1)$ \\
Total & 73 & 32 \\
\hline
\end{tabular}

Table 2

Seroprevalence of $T$. evansi and EIAV in different groups of infection in F1 farm of the southern Pantanal in two distinct periods. NN - negative animals for both $T$. evansi and AIE virus infection; PN - positive animals only for T. evansi infection; NP - positive animals only for AIE virus infection; PP - co-infected animals by T. evansi and AIE virus. The absolute number is followed by the percentage in parenthesis. Statistical differences at $\mathrm{p}<0.005$ are marked with asterisks.

\begin{tabular}{lll}
\hline Groups & Beginning of the rainy season & End of the flooded season \\
\hline NN & $31(28.7)^{*}$ & $17(15.7)^{*}$ \\
NP & $15(13.9)^{*}$ & $10(9.3)^{*}$ \\
PN & $44(40.7)$ & $57(52.8)$ \\
PP & $18(16.7)^{*}$ & $24(22.2)^{*}$ \\
Total & 108 & 108 \\
\hline
\end{tabular}

of infections, individually or together, in hematological parameters, we applied the Kruskal-Wallis test variance in the sampled horses arranged as the following:

NN - negative animals for both T. evansi and AIE virus infection;

PN - positive animals only for T. evansi infection;

$\mathrm{NP}$ - positive animals only for AIE virus infection;

PP - co-infected animals by T. evansi and AIE virus.

To verify if there was an influence of the seasons on health profile of rearing untrained animals and working tamed animals from F1, we used the Wilcoxon test. The phi coefficient was used to test if there was a correlation between these categories and the presence and absence of infections. To check if there was a significant difference in the prevalence of infection by T. evansi between seasons (December and April), we used the Kappa test. All analyzes were performed with the Bioestat Program 5.0 and we considered a significance of $95 \%$.

\section{Results}

We observed differences in seroprevalence of T. evansi and EIAV infections, individually or together, according to the farms. The negative animals for both infectious agents (NN) represented the major group in F1 (37\%), and the smallest group in F2 (18.8\%) (Table 1). Furthermore, we recorded higher EIAV seroprevalence (56\%) (including NP and PP horses) in F2, compared to F1 (38\%). In addition, we did not observe patent parasitaemia of $T$. evansi or clinical signs suggestive of either the two infections.

Althought we observed high seroprevalences of horses infected only by T. evansi (PN) in beginning of flood season (40.7\%) and at the end of the rainy season (52.8\%) (Table 2), our results showed a significant difference of $T$. evansi infection between young and working animals in the beginning of the rainy season (December) (Table 3). We recorded the increase of seroprevalence in working horses at the end of the flooded season due to the seroconversion of 19 horses from December 2012 to April 2013, corresponding to $17 \%$ of the 108 analyzed animals. No animal showed clinical symptom of tripanosomiasis due to T. evansi, and only one young horse presented patent $T$. evansi parasitaemia in December, as detected by MHCT.
Table 3

Seroprevalence of T. evansi and EIAV in young and working horses of F1 farm of the southern Pantanal in two distinct periods. The absolute number is followed by the percentage in parenthesis.

\begin{tabular}{|c|c|c|c|}
\hline & \multicolumn{2}{|c|}{ Beginning of the rainy season } & \multirow[t]{2}{*}{ p value } \\
\hline & Young horses & Working horses & \\
\hline T. evansi & $41(70.7)$ & $21(42.0)$ & $p=0.0049$ \\
\hline \multirow[t]{3}{*}{ EIAV } & $9(15.5)$ & $24(48.0)$ & $p=0.0006$ \\
\hline & \multicolumn{2}{|c|}{ End of the flooded season } & \\
\hline & Young horses & Working horses & \\
\hline T. evansi & $47(81.0)$ & $34(68.0)$ & $\mathrm{p}=0.1812$ \\
\hline EIAV & $10(17.2)$ & $24(48.0)$ & $p=0.0013$ \\
\hline
\end{tabular}

Table 4

Hematological mean values (averages and standard deviation) between horses from F1 and F2 of the southern Pantanal. of The p-values were obtained by the Mann-Whitney test.

\begin{tabular}{llll}
\hline Hematological Values & F1 & F2 & p-value \\
\hline PCV $(\%)$ & $31.8( \pm 5.33)$ & $30.6( \pm 3.71)$ & 0.3563 \\
$\operatorname{RBC}\left(\times 10^{6} / \mu \mathrm{L}\right)$ & $7.19( \pm 2.14)$ & $5.6( \pm 1.37)$ & $<\mathbf{0 . 0 0 0 1}$ \\
MCV $(\mathrm{ft})$ & $46.8( \pm 12.3)$ & $57.6( \pm 13.4)$ & $\mathbf{0 . 0 0 0 4}$ \\
WBC $\left(\times 10^{6} / \mu \mathrm{L}\right)$ & $12.343( \pm 3.238)$ & $10.237( \pm 2.805)$ & $\mathbf{0 . 0 0 0 6}$ \\
Lymphocytes $\left(\times 10^{6} / \mu \mathrm{L}\right)$ & $7.928( \pm 2.921)$ & $5.016( \pm 1.600)$ & $<\mathbf{0 . 0 0 0 1}$ \\
Neutrophils $\left(\times 10^{6} / \mu \mathrm{L}\right)$ & $3.594( \pm 2.310)$ & $4.192( \pm 1.831)$ & 0.1026 \\
Eosinophils $\left(\times 10^{6} / \mu \mathrm{L}\right)$ & $503( \pm 402)$ & $552( \pm 321)$ & 0.3315 \\
Monocytes $\left(\times 10^{6} / \mu \mathrm{L}\right)$ & $309( \pm 259)$ & $449( \pm 449)$ & 0.0565 \\
\hline
\end{tabular}

We found that the seroprevalence of horses infected only by EIAV (NP) was smallest in the two periods of sampling (13.9\% and 9.3\%) (Table 2). Furthermore, the seroprevalence of working horses infected by EIAV was the same in December and April (48\%), only one young animal seroconverted (Table 3 ). Moreover, our results showed a positive correlation between EIAV infection and working horses in both beginning of flood season and at the end of the rainy season.

Our results suggest a better general health profile in F1 horses because the indicators of health condition and immune active response (RBC and lymphocytes counts) were significantly different in horses of F1 than in F2 horses (Table 4).

The influence of infections, individually or together, in hematological parameters, showed that in the beginning of the rainy season, the health conditions expressed by RBC counts and PCV values, in horses at F1 differed statistically among the groups. The infection by EIAV (NP) and co-infection (PP) promoted a significant decrease in RBC averages $\left(7.10 \times 10^{6} / \mu \mathrm{L}\right.$ and $7,48 \times 10^{6} / \mu \mathrm{L}$ respectively) comparing to horses only infected by $T$. evansi (PN) and non-infected $(\mathrm{NN})\left(8.84 \times 10^{6} / \mu \mathrm{L}\right.$ and $8.18 \times 10^{6} / \mu \mathrm{L}$ respectively) $(\mathrm{p} \leq 0.02)$. However, horses infected only by T. evansi (PN) showed lower average values of PCV (29\%).

We also observed that the health of NP and PP horses at the end of the flooded season (April 2013) was severely affected. In fact, in this period, the PCV values of horses infected only by EIAV (NP) and co-infected (PP) horses (33.3\% and 35\% respectively) was smaller than NN (39.6\%) and PN (37.6\%) groups $(\mathrm{p}<0.02)$ Moreover, the RBC mean of NP horses $\left(7.19 \times 10^{6} / \mu \mathrm{L}\right)$ was lower than in the PN group $\left(9.10 \times 10^{6} / \mu \mathrm{L}\right)(\mathrm{p}<0.05)$, as well as, the RBC mean of the PP group $\left(7.22 \times 10^{6} / \mu \mathrm{L}\right)$ was lower than the PN and NN $\left(8.48 \times 10^{6} / \mu \mathrm{L}\right)$ groups $(\mathrm{p}=0.05)$. Furthermore, NP horses presented a significant higher infection response, expressed by neutrophils mean $(8411 / \mu \mathrm{L})$, than the PN $(7917 / \mu \mathrm{L})$ and PP group $(6580 / \mu \mathrm{L})(\mathrm{p}<0.01)$

In addition, we observed that young animals present means of PCV, RBC, WBC and lymphocyte significantly higher, and MCV significantly lower, than the working animals, in the beginning and 
Table 5

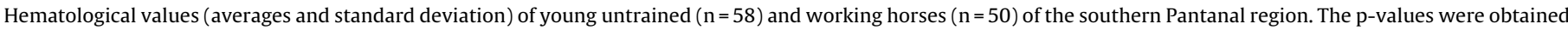
by the Mann-Whitney test.

\begin{tabular}{|c|c|c|c|c|c|c|}
\hline \multirow[t]{2}{*}{ Hematological values } & \multicolumn{3}{|c|}{ Beginning of the rainy season } & \multicolumn{3}{|c|}{ End of the flooded season } \\
\hline & young untrained & working horses & p-value & young untrained & working horses & p-value \\
\hline $\operatorname{PCV}(\%)$ & $38.8( \pm 3.3)$ & $34.4( \pm 5.4)$ & $<0.0001$ & $38.3( \pm 3.7)$ & $35.3( \pm 6.1)$ & 0.0025 \\
\hline $\mathrm{RBC}\left(\times 10^{6} / \mu \mathrm{L}\right)$ & $8.73( \pm 1.29)$ & $7.18( \pm 1.53)$ & $<0.0001$ & $8.87( \pm 1.51)$ & $7.05( \pm 1.68)$ & $<0.0001$ \\
\hline $\operatorname{MCV}(\mathrm{ft})$ & $45.2( \pm 6.2)$ & $48.8( \pm 6.1)$ & 0.0027 & $44.3( \pm 7.7)$ & $51.7( \pm 10.8)$ & $<0.0001$ \\
\hline $\mathrm{WBC}\left(\times 10^{6} / \mu \mathrm{L}\right)$ & $14.366( \pm 4.536)$ & $12.336( \pm 2.522)$ & 0.0015 & $17.984( \pm 6.212)$ & $11.848( \pm 3.275)$ & $<0.0001$ \\
\hline Lymphocytes $\left(\times 10^{6} / \mu \mathrm{L}\right)$ & $8.563( \pm 3.520)$ & $6.292( \pm 2.559)$ & $<0.0001$ & $8.019( \pm 3.972)$ & $3.965( \pm 1.747)$ & $<0.0001$ \\
\hline Neutrophils $\left(\times 10^{6} / \mu \mathrm{L}\right)$ & $4.660( \pm 2.251)$ & $4.968( \pm 2.380)$ & 0.5962 & $7.748( \pm 4.634)$ & $6.410( \pm 1.822)$ & 0.0012 \\
\hline Eosinophils $\left(\times 10^{6} / \mu \mathrm{L}\right)$ & $620( \pm 432)$ & $628( \pm 387)$ & 0.9044 & $775( \pm 687)$ & $646( \pm 355)$ & 0.8198 \\
\hline Monocytes $\left(\times 10^{6} / \mu \mathrm{L}\right)$ & $524( \pm 459)$ & $448( \pm 409)$ & 0.2782 & $1.584( \pm 1.293)$ & $788( \pm 741)$ & $<0.0001$ \\
\hline
\end{tabular}

in the end of the rainy season. However, neutrophils and monocytes counts (indicators of infection response) were significantly higher in young animals than the working animals at the end of the flooding period (Table 5).

\section{Discussion}

In relation to animal health, the differences in hematological parameters between rearing young animals and working horses are expected. In this sense, as observed in this study, young animals commonly have the health condition indicators (PCV and RBC) and active immune response (lymphocytes) higher than working animals (Feldman et al., 2000; Ribeiro et al., 2008). However, the infection response indicators (neutrophils and monocytes) were significantly higher at the end of flooded period and can be associated with environmental stress because grasslands are flooded, concentrating the animals and decreasing the availability of native forages (Pozer and Nogueira, 2004). These factors contribute to reduce the physical condition of the horses, which predispose to parasitic infectious agents (Nelson and Demas, 1996; Tompkins and Begon, 1999). The high counts of monocytes and neutrophils recorded at the end of the flooded period, even in the NN group (horses without T. evansi and EIAV infection), indicated that other agents recorded in the studied area as equine encephalitis (Pauvolid-Corrêa et al., 2014), influenza (Gaíva e Silva et al., 2014), Rickettsias (Nieri-Bastos et al., 2014), and Leptospira spp. (Jorge et al., 2011) could also be affecting the health of horses.

Our results showed that co-infection by T. evansi and EIAV can aggravate the health condition of studied horses, as recorded by low RBC and PCV mean values of PP group in the beginning of rainy season and in the end of flood season. Indeed, the "protozoan/retrovirus" associations in different species have shown that the health of hosts may become compromised (Da-Cruz et al., 1992; Alvar et al., 1997; Sartori et al., 2002; Silveira et al., 2013). However, as previously discussed, the presence of differents infectious agents in a particular host not always constitutes a risk to your health (Tshikuka et al., 1996; Rohani et al., 2008).

The differences between the prevalence of infections and coinfections observed between farms were probably a consequence of the management to which horses were subjected, exemplified by the largest prevalence of negative animals for both infections (NN) in F1 farm (37\%), while the NN animals were the lowest in F2 farm (19\%). The lack of animal handling and care, exemplified by sharing fomites and low availability of pasture in F2, possibly also reflected in the difference of EIAV seroprevalence ( $F 1=38 \%$, and $F 2=56 \%$ ).

Additionally, the difference in management observed between farms has greater influence on the health status than the infections. We found a better health profile in the F1 horses, as the average values of RBC, WBC, and lymphocytes were significantly higher in F1 than in F2. On the other hand, the poor physical condition observed in F2 animals was the determinant factor that influenced the health profile (observed in hematological parameters) between infected and uninfected horses, including the NN group.
Although we have not found patent $T$. evansi parasitaemia or clinical signs suggestive of either of the two infections, the influence of T. evansi on the health condition was evidenced by lower values of PCV and RBC, as shown in the NP group in the end of flooded season. In fact, horses infected by $T$. evansi can present subclinical infections with mild anemia in this area (Herrera et al., 2004). Actually, alternation between the "epizootic clinical" and "inter-epizootic subclinical" phases (characterized by very low parasitaemias) on a temporal scale is an epidemiological characteristic reported on endemic areas for salivarian trypanosomes (Desquesnes, 2004). As we found lower health condition indicators on the end of flooded season, the environmental circumstances should not be ruled out as a risk factor on the health of animals. Indeed, the clinical disease is an eventual outcome of the parasite-host-environment association (Araújo et al., 2003). Furthermore, EIAV similarly has also influenced the health condition in the studied horses since the animals infected by the virus (NP and PP) showed lower RBC and PCV values in December and April respectively. The etiology and pathogenesis of anemia is complex and cannot be accurately represented by one simple mechanism, and in most cases it is due to two or more causative agents rather than a single one (Távora et al., 2015).

Our results showed that horses are exposed to mechanical transmission by horseflies since birth, as observed by the highest seroprevalences of T. evansi infection in young horses: $70.7 \%$ and $81 \%$ in beginning of the raining season and the end of flooded season respectively. Really, $T$. evansi is maintained by a wide variety of species of wild and domestic hosts in the Pantanal (Nunes and Oshiro, 1990; Silva et al., 1995a; Herrera et al., 2007, 2008). Moreover, during the summer, there was a great occurrence of vectors (Barros and Foil, 1999) and the animals were concentrated to non-flooded areas, favoring the vector transmission. This enzootic character may have strongly influenced the seroconversion of 19 horses from December 2012 to April 2013, supplementing that the flooded period represents a risk factor for T. evansi infection, as previously reported (Silva et al., 1995a; Herrera et al., 2004).

Concerning EIAV, since only one animal seroconverted during the summer, period in which the highest density of horseflies has been reported (Barros, 2001; Barros and Foil, 2007), we predict that the risk factor of EIAV transmission would be more associated to the different farms management than to blood-sucking flies. In this sense, our results together with Borges et al. (2013) showed that the EIAV transmission in different regions of Pantanal is strongly associated with human activities.

An important point that should not be ruled out in the health status of infected animals refers to the seasonal weather in the Pantanal wetland that significantly changes the landscape: the dynamics of floods and droughts directly influences the nutritional and immune status of horses. These ecological relationships are not static but dynamic in time and space (Vannier-Santos and Lenzi, 2011). Consequently, it is not expected an epidemiological pattern of a given infectious, with re-emergence of severe outbreaks at irregular time intervals, as previously registered (Rwambo et al., 1990; Silva et al., 1995b; Osório et al., 2008). In addition, as men- 
tioned, the co-occurrence of other infectious agents may result in situations where T. evansi and EIAV, alternatively, influence the health of the horses. Considering the importance of horse breeding as an essential in the Pantanal cattle ranches, we suggest that the management of horses from Pantanal region should be include nutritional and sanitary care. In the case of horses infected by $T$. evansi, animals must be treated. Related to EIAV, as there is no treatment for retrovirus, and seropositive animals are source of infection, they must be removed.

\section{Conflict of interest}

None of the authors have any conflict of interests in this manuscript.

\section{References}

Alvar, J., Cañavate, C., Gutiérrez-Solar, B., Jiménez, M., Laguna, F., López-Vélez, R., Molina, R., Moreno, J., 1997. Leishmania and human immunodeficiency virus coinfection: the first 10 years. Clin. Microbiol. Rev. 10, 298-319.

Araújo, A., Jansen, A.M., Bouchet, F., Reinhard, K., Ferreira, L.F., 2003. Parasitism, the diversity of dife, and paleoparasitology. Mem. Inst. Oswaldo Cruz 98, 5-11.

Baldacchino, F., Muenworn, V., Desquesnes, M., Desoli, F., Charoenviriyaphap, T., Duvallet, G., 2013. Transmission of pathogens by Stomoxys flies (Diptera, Muscidae): a review. Parasite 20, 26

Baldacchino, F., Desquesnes, M., Mihok, S., Foil, L.D., Duvallet, G., Jittapalapong, S., 2014. Tabanids: neglected subjects of research, but important vectors of disease agents! Infect. Genet. Evol. 28, 596-615.

Barros, A.T., Foil, L., 1999. Seasonal occurrence and relative abundance of Tabanidae (Diptera) from the Pantanal region, Brazil. Mem. Entomol. Int. 14, 387-394.

Barros, A.T., Foil, L.D., 2007. The influence of distance on movement of tabanids (Diptera: Tabanidae) between horses. Vet. Parasitol. 144, 380-384.

Barros, A.T., 2001. Seasonality and relative abundance of Tabanidae (Diptera) captured on horses in the Pantanal, Brazil. Mem. Inst. Oswaldo Cruz 96 (7), 917-923.

Borges, A.M., Silva, L.G., Nogueira, M.F., Oliveira, A.C., Segri, N.J., Ferreira, F., Witter, R., Aguiar, D.M., 2013. Prevalence and risk factors for Equine Infectious Anemia in Poconé municipality, northern Brazilian Pantanal. Res. Vet. Sci. 95, 76-81.

Camargo, M.E., 1964. Improved technique of indirect immunofluorescence for serological diagnosis for toxoplasmosis. Rev. Inst. Med. Trop. São Paulo 6, $117-118$.

Cheevers, W.P., McGuire, T.C., 1985. Equine infectious anemia virus: immunopathogenesis and persistence. Rev. Infect. Dis. 7, 83-88.

Coggins, L., Norcross, N.L., Nusbaum, S.R., 1972. Diagnosis of equine infectious anemia by immunodiffusion test. Am. J. Vet. Res. 33, 11-18.

Cook, R.F., Leroux, C., Issel, C.J., 2013. Equine infectious anemia and equine infectious anemia virus in 2013: a review. Vet. Microbiol. 167, 181-204.

Cox, F.E., 2001. Concomitant infections, parasites and immune responses. Parasitology 122, 23-38.

Dávila, A.M., Herrera, H.M., Schlebinger, T., Souza, S.S., Traub-Cseko, Y.M., 2003. Using PCR for unraveling the cryptic epizootiology of livestock trypanosomosis in the Pantanal, Brazil. Vet. Parasitol. 117 (1-2), 1-13.

Da-Cruz, A.M., Machado, E.S., Menezes, J.A., Rutowitsch, M.S., Coutinho, S.G., 1992. Cellular and humoral immune responses of a patient with American cutaneous leishmaniasis and AIDS. Trans. R. Soc. Trop. Med. Hyg. 86, 511-512.

Desquesnes, M., 2004. Livestock Trypanosomoses and Their Vectors in Latin America. OIE (World Organization for Animal Health), Paris.

Feldman, B.F., Zinkl, J.G., Jain, N.C., 2000. Schalm's Veterinary Hematology. Wiley-Blackwell, Oxford.

Gaíva e Silva, L., Borges, A.M., Villalobos, E.M., Lara Mdo, C., Cunha, E.M., de Oliveira, A.C., Braga, I.A., Aguiar, D.M., 2014. Prevalence of antibodies against influenza virus in non-vaccinated equines from the Brazilian Pantanal. Rev. Inst. Med. Trop. São Paulo 56, 487-492.

Gardiner, P.R., Mahmoud, M.M., 1990. Salivarian trypanosomes. In: Baker, J.R. (Ed.), Causing Disease in Livestock Outside Sub-Saharan Africa Parasitc Protozoa. Academic Press, New York, pp. 1-68.

Grenfell, B.T., Dobson, A.P., 1995. Ecology of Infectious Diseases in Natural Populations. Cambridge University Press, Cambridge.

Herrera, H.M., Dávila, A.M., Norek, A., Abreu, U.G., Souza, S.S., D’Andrea, P.S., Jansen, A.M., 2004. Enzootiology of Trypanosoma evansi in Pantanal, Brazil. Vet. Parasitol. 125, 263-275.

Herrera, H.M., Norek, A., Freitas, T.P., Rademaker, V., Fernandes, O., Jansen, A.M. 2005. Domestic and wild mammals infection by Trypanosoma evansi in a pristine area of the Brazilian Pantanal region. Parasitol. Res. 96 (2), 121-126.

Herrera, H.M., Rademaker, V., Abreu, U.G., D’Andrea, P.S., Jansen, A.M., 2007. Variables that modulate the spatial distribution of Trypanosoma cruzi and Trypanosoma evansi in the Brazilian Pantanal. Acta Trop. 102, 55-62.

Herrera, H.M., Abreu, U.G., Keuroghlian, A., Freitas, T.P., Jansen, A.M., 2008. The role played by sympatric collared peccary (Tayassu tajacu), white-lipped peccary (Tayassu pecari), and feral pig (Sus scrofa) as maintenance hosts for
Trypanosoma evansi and Trypanosoma cruzi in a sylvatic area of Brazil. Parasitol. Res. 103, 619-624.

Hoare, C.A., 1972. The Trypanosomes of Mammals: A Zoological Monograph. Blackwell, Oxford.

Issel, C.J., Coggins, L., 1979. Equine infectious anemia: current knowledge. J. Am. Vet. Med. Assoc. 174, 727-733.

Issel, C.J., Foil, L.D., 1984. Studies on equine infectious anemia virus transmission by insects. J. Am. Vet. Med. Assoc. 184, 293-297.

Jorge, R.S., Ferreira, F., Ferreira Neto, J.S., Vasconcellos Sde, A., Lima Ede, S., Morais, Z.M., Souza, G.O., 2011. Exposure of free-ranging wild carnivores, horses and domestic dogs to Leptospira spp. in the northern Pantanal, Brazil. Mem. Inst. Oswaldo Cruz 106, 441-444.

Junk, W.J., Cunha, C.N., Wantzen, K.M., Petermann, P., Strüssmann, C., Marques, M.I., Adis, J., 2006. Biodiversity and its conservation in the Pantanal of Mato Grosso, Brazil. Aquat. Sci. 68, 278-309.

Lanham, S.M., Godfrey, D.G., 1970. Isolation of salivarian trypanosomes from man and other mammals using DEAE-cellulose. Exp. Parasitol. 28, 521-534.

McKay, D.M., 2006. The beneficial helminth parasite? Parasitology 132, 1-12.

Nelson, R.J., Demas, G.E., 1996. Seasonal changes in immune function. Q. Rev. Biol. 71, 511-548.

Nieri-Bastos, F.A., Lopes, M.G., Cançado, P.H., Rossa, G.A., Faccini, J.L., Gennari, S.M., Labruna, M.B., 2014. Candidatus Rickettsia andeanae, a spotted fever group agent infecting Amblyomma parvum ticks in two Brazilian biomes. Mem. Inst. Oswaldo Cruz 109, 259-261.

Nunes, V.L., Oshiro, E.T., 1990. Trypanosoma (Trypanozoon) evansi in the coati from the Pantanal region of Mato Grosso do Sul State, Brazil. Trans. R. Soc. Trop. Med. Hyg. 84, 692.

Osório, A.L., Madruga, C.R., Desquesnes, M., Soares, C.O., Ribeiro, L.R., Costa, S.C., 2008. Trypanosoma (Duttonella) vivax: its biology, epidemiology, pathogenesis, and introduction in the New World-a review. Mem. Inst. Oswaldo Cruz 103, $1-13$.

Pauvolid-Corrêa, A., Campos, Z., Juliano, R., Velez, J., Nogueira, R.M., Komar, N., 2014. Serological evidence of widespread circulation of West Nile virus and other flaviviruses in equines of the Pantanal, Brazil. PLoS Negl. Trop. Dis. 8, e2706.

Pfaff, A.W., Candolfi, E., 2003. Immune responses to protozoan parasites and its relevance to dianosis in immunocompromised patients. Eur. J. Protistol. 39, $428-434$.

Pozer, C.G., Nogueira, F., 2004. Flooded native pastures of the northern region of the Pantanal of Mato Grosso: biomass and primary productivity variations. Braz. J. Biol. 64, 859-866.

Ribeiro, C.R., Fagliari, J.J., Galera, P.D., Oliveira, A.R., 2008. Hematological profile of healthy Pantaneiro horses. Arq. Bras. Med. Vet. Zootec. 60, 492-495.

Rohani, P., Wearing, H.J., Vasco, D.A., Huang, Y., 2008. Understanding host-multipathogen systems: modelling the interaction between ecology and immunology. In: Ostfeld, R.S., Keesing, F., Eviner, V.T. (Eds.), Disease Ecology: Effects of Ecosystems on Disease and of Disease on Ecosystems. Princeton University Press, Princeton, pp. 48-70

Rwambo, P.M., Issel, C.J., Adams Jr., W.V., Hussain, K.A., Miller, M., Montelaro, R.C., 1990. Equine infectious anemia virus (EIAV) humoral responses of recipient ponies and antigenic variation during persistent infection. Arch. Virol. 111, 199-212.

Sartori, A.M., Neto, J.E., Nunes, E.V., Braz, L.M., Caiaffa-Filho, H.H., Oliveira Jr., Oda C., Neto, V.A., Shikanai-Yasuda, M.A., 2002. Trypanosoma cruzi parasitemia in chronic Chagas disease: comparison between human immunodeficiency virus (HIV)-positive and HIV-negative patients. J. Infect. Dis. 186, 872-875.

Seidl, A.F., Moraes, A.S., Silva, R.A., 2001. Trypanosoma evansi control and horse mortality in the Brazilian Pantanal. Mem. Inst. Oswaldo Cruz 96, 599-602.

Silva, R.A., Arosemena, N.A., Herrera, H.M., Sahib, C.A., Ferreira, M.S., 1995a. Outbreak of trypanosomosis due to Trypanosoma evansi in horses of Pantanal Mato-grossense, Brazil. Vet. Parasitol. 60, 167-171.

Silva, R.A., Herrera, H.M., Barros, A.T.M., 1995b. Trypanosomosis outbreaks due to Trypanosoma evansi in the Pantanal, Brazil: a preliminary approach on risk factors. Rev. Elev. Med. Vet. Pays Trop. 4, 315-319.

Silva, R.A., Davila, A.M.R., Iversson, L.B., Abreu, U.P.G., 1999. Equine viral diseases in the Pantanal, Brazil: studies carried out from 1990 to 1995. Rev. Elev. Med. Vet. Pays Trop. 52, 9-12.

Silveira, P., Marin, S.Y., Moreira, P.A., Tocantins, B.B., Lacorte, G., Paixão, T.A., Martins, N.R., Braga, É.M., 2013. Interactions of Plasmodium juxtanucleare and chicken anaemia virus: establishing a model. Parasitology 140, 1777-1788.

Singer, M., 2010. Pathogen-pathogen interaction: a syndemic model of complex biossocial processes in disease. Virulence 1, 10-18.

Távora, L.G., Nogueira, M.B., Gomes, S.T., 2015. Visceral leishmaniasis/HIV co-infection in northeast Brazil: evaluation of outcome. Braz. J. Infect. Dis. 19, 651-656.

Tompkins, D.M., Begon, M., 1999. Parasites can regulate wildlife populations Parasitol. Today 15, 311-313.

Tshikuka, J.G., Scott, M.E., Gray-Donald, K., Kalumba, O.N., 1996. Multiple infection with Plasmodium and helminths in communities of low and relatively high socio-economic status. Ann. Trop. Med. Parasitol. 90, 277-293.

Vannier-Santos, M.A. Lenzi, H.L., 2011. Parasites or cohabitants: cruel omnipresente usurpers or creative éminences grises? J. Parasitol. Res. 2011, 214174.

Woo, P.T., 1970. The haematocrit centrifuge technique for the diagnosis of African trypanosomiasis. Acta Trop. 27, 384-386. 